\title{
Comparison of Furazolidone Versus Clarithromycin for Eradication of Helicobacter Pylori Infection: A Randomized Multicenter Clinical Trial
}

\author{
Pezhman Alavinejad $^{1}$, Seyed Saeed Seiedian ${ }^{1}$, Kave Ebadi Borna ${ }^{2}$, \\ Eskandar Hajiani $^{1}$, Maryam Lajmirnia ${ }^{1}$, Saeed Hesam ${ }^{3}$ \\ ${ }^{1}$ Alimentary Tract Research Center, Imam Khomeini Hospital Clinical Research \\ Development Unit, Ahvaz Jundishapur University of Medical Sciences, Ahvaz, Iran. \\ ${ }^{2}$ GI ward, Ahvaz Amir-Almomenin Hospital, Ahvaz Iran . \\ ${ }^{3}$ Department of biostatics and epidemiology school of health, Ahvaz Jundishapur \\ University of medical sciences, Ahvaz, Iran .
}

Corresponding Author Pezhman Alavinejad

Mobile:

00989161115880

E mail:

Pezhmanalavinejad@g mail.com

Key words:

$H P$, eradication,

Furazolidone,

clarithromycin

quadruple therapy
Background and study aims: to evaluate efficacy of Furazolidone versus clarithromycin in quadruple therapy for eradication of Helicobacter Pylori (HP) infection .

Patients and Method: During a period of six months, all of the cases with HP infection in 3 referral tertiary centers included. The participants randomly allocate to receive either clarithromycin or Furazolidone base quadruple regimen. For all of the participants pantoprazole continued for 4 more weeks and after 1 to 2 weeks of off therapy, they underwent Urea Breath Test to prove eradication.

Results: Overall 386 patients included (165 male (42\%), average age 44.2y). They diagnosed as non-ulcer dyspepsia (311 cases), peptic ulcer disease (34 cases) and intestinal metaplasia (45 cases). The participants randomly allocated to groups $\mathrm{A} \& \mathrm{~B}$ to receive either clarithromycin or Furazolidone. In groups A and B, $80.9 \%$ \& $82.1 \%$ of participants achieved eradication respectively $(\mathrm{P}=0.819)$. During study, there was not any major complication but $3.1 \%$ of participants in each group reported minor side effects including bitter taste, Gastrointestinal (GI) upset, headache and or vertigo. In sub group analysis, the eradication rate of clarithromycin among patients with nonulcer dyspepsia, peptic ulcer disease (PUD) and intestinal metaplasia were $80 \%, 100 \%$ \& $55.6 \%$ respectively. These figures in group B (Furazolidone) were $80.7 \%, 100 \%$ \& $85.7 \%$ respectively $(\mathrm{P}=$ $0.906,0 \& 0.162)$. Overall, there was no significant difference in success rate between clarithromycin and Furazolidone but in cases with intestinal metaplasia, the positive results with Furazolidone was more $(85.7 \%$ vs. $55.6 \%)$.

Conclusion: In areas with high rate of resistance to clarithromycin, Furazolidone could be a potential candidate in HP eradication regimen and in cases with intestinal metaplasia; Furazolidone could be even more efficient than clarithromycin.

\section{INTRODUCTION}

Helicobacter pylori ( HP) which infect almost half of the world population is the main offender in creation of disorders such as gastritis and peptic ulcer disease and has known as a major risk factor of gastric cancer [1, $\mathbf{2}, \mathbf{3}, 4]$. Though the rate of HP infection has decreased in developed countries, its prevalence is still increasing in developing communities probably because of poor socioeconomic level and life style [2, $5,6,7,8,9]$.

In recent decades, a large number of associations with nongastric diseases and HP infection have been reported beside gastric problems that further emphasize on importance of HP detection and eradication $[\mathbf{1 0}, \mathbf{1 1}, \mathbf{1 2}]$.

On the other hand, Prevalence of $\mathrm{H}$. pylori antibiotic resistance is increasing worldwide, a main factor that affecting efficacy of current therapeutic regimens [13]. Antibiotic 
resistance in Helicobacter pylori is the major cause of eradication failure and an ever-changing issue. Primary $\mathrm{H}$. pylori susceptibility patterns are becoming less predictable and currently, high $(\geq 20 \%)$ clarithromycin resistance rates have been observed in the developed countries [14]. The resistance rate is even more in developing countries and is the main reason for eradication failure $[15,16,17]$. This emerging pattern of resistant, necessitate evaluating different therapeutic regimens for clinical purposes [18]. In this regard, a potential substitute could be Furazolidone based regimen as a well-established and inexpensive antibiotic, which is also shown to be a potentially good alternative to metronidazole, especially in areas where metronidazole resistance is common [19, 20, 21]. In this randomized multi centric clinical trial, we evaluated efficacy of Furazolidone versus clarithromycin as quadruple therapy for eradication of HP infection.

\section{METHODS}

During a 6 months period, all of the cases who had attended outpatient clinics of 3 referral tertiary centers with complain of dyspepsia and their HP infection diagnosed based on tissue biopsy specimen included and allocate randomly into groups A \& B. Participants in group A treated with clarithromycin base quadruple regimen (Pantoprazole $40 \mathrm{mg}$ bid, Clarithromycin 500mg BID, amoxicillin 1gr BID $\&$ Bismuth sub salicylate 240mg BID) and those in group B received Furazolidone base quadruple regimen (Pantoprazole 40mg BID, Furazolidone 100mg BID, Amoxicillin 1gr BID \& Bismuth sub salicylate $240 \mathrm{mg}$ BID) for 2 weeks. Then all of the cases prescribed pantoprazole $40 \mathrm{mg}$ BID for 4 more weeks and after 1 to 2 weeks of off therapy (week 7 or 8), they underwent Urea Breath Test (UBT) to prove eradication. Then the rate of eradication and complication between 2 groups determined and compared.

Exclusion criteria include severe heart failure, chronic renal failure, pulmonary insufficiency, advanced chronic liver diseases including viral hepatitis, active malignancy in last 3 years, history of surgery on upper GI tract, consumption of antibiotics recent 4 weeks or HP eradication in last six months, uncontrolled diabetes mellitus, any organ transplantation, past history of allergy to any of the medications used in HP eradication regimen, any history of esophageal varices, pregnancy or breast feeding for women and warfarin or clopidogrel consumption.

Inclusion criteria include confirmation of HP infection by endoscopic biopsy, age range between 18 to 75 year old with clinical and endoscopic diagnosis of Peptic Ulcer disease (PUD), non-ulcer dyspepsia or intestinal metaplasia.

All statistical analyses were performed with Statistical Package for Social Sciences (SPSS Inc., Chicago, IL, USA) Program version 19 for windows. The differences with $\mathrm{P}$ values $<0.05$ were considered as significant.

\section{RESULTS}

During study period, overall 386 patients included (165 male (42\%), average age 44.2y, age range 18 - 75). Based on their endoscopic findings and pathology report they classified as non-ulcer dyspepsia (311 cases), peptic ulcer disease (30 cases) and intestinal metaplasia (45 cases). The demographic characters of participants mentioned in table 1 . The participants randomly allocated to groups A \& B to receive either clarithromycin or Furazolidone base HP quadruple therapeutic regimen. At the end of intervention, all of them evaluated by UBT to confirm eradication. At the end of intervention, 65 cases in group A and 89 cases in group B did not returned for their follow up and they omitted in per protocol analysis (PP) but supposed as eradication failure in intention to treat (ITT) analysis (figure 1).

In groups $\mathrm{A}$ and $\mathrm{B}, 80.9 \% \& 82.1 \%$ of participants achieved eradication respectively (univariable $\mathrm{P}=0.819$, multi variable $\mathrm{P}=0.691$, per protocol analysis (PP)). In intention to treat (ITT) analysis, these figures were $79 \%$ in group $\mathrm{A}$ and $80.5 \%$ in group $\mathrm{B}$ respectively $(\mathrm{P}=0.81)$. During study, there was not any major complication but $3.1 \%$ of participants in each group reported minor side effects including bitter taste, GI upset, headache and or vertigo.

In sub group analysis, the eradication rate of clarithromycin among patients with non-ulcer dyspepsia, PUD and intestinal metaplasia were $80 \%, 100 \%$ \& $55.6 \%$ respectively. These figures in group B (Furazolidone) were $80.7 \%, 100 \%$ \& $85.7 \%$ respectively $(\mathrm{P}=0.906,0 \& 0.162$; table 2). Overall, there was no significant difference in 
success eradication rate between clarithromycin and Furazolidone in any of the clinical categories but among those with intestinal metaplasia, the positive results with Furazolidone was more efficient (85.7\% vs. 55.6\%).

Table (1): Demographic characters of participants based on clinical diagnosis .

\begin{tabular}{|l|c|c|c|}
\hline Clinical diagnosis & Number & Average Age (y) & Male/Female \\
\hline Non-ulcer dyspepsia & 311 & 43.1 & $125 / 186$ \\
\hline Peptic Ulcer disease & 34 & 44.02 & $22 / 12$ \\
\hline Intestinal metaplasia & 45 & 51.6 & $18 / 27$ \\
\hline Overall & 390 & 46.24 & $165 / 225$ \\
\hline
\end{tabular}

Table (2): Subgroup analysis of eradication rate by clarithromycin and Furazolidone (C: clarithromycin, F: Furazolidone, PUD: peptic ulcer disease).

\begin{tabular}{|l|c|c|c|c|}
\hline Clinical diagnosis & $\begin{array}{c}\text { Therapeutic } \\
\text { regimen }\end{array}$ & Eradication rate & Failure rate & \multirow{2}{*}{ P value } \\
\hline \multirow{2}{*}{ Non ulcer dyspepsia } & $\mathrm{C}$ & $84(80 \%)$ & $21(20 \%)$ & \multirow{2}{*}{0.906} \\
\cline { 2 - 4 } & $\mathrm{F}$ & $71(80.7 \%)$ & $17(19.3 \%)$ & \multirow{2}{*}{-} \\
\cline { 2 - 4 } PUD & $\mathrm{C}$ & $17(100 \%)$ & $0(0 \%)$ & \multirow{2}{*}{0.162} \\
\hline \multirow{2}{*}{ Intestinal Metaplasia } & $\mathrm{F}$ & $4(100 \%)$ & $0(0 \%)$ & $4(44.4 \%)$ \\
\cline { 2 - 4 } & $\mathrm{C}$ & $5(55.6 \%)$ & $2(14.3 \%$ & \\
\hline
\end{tabular}

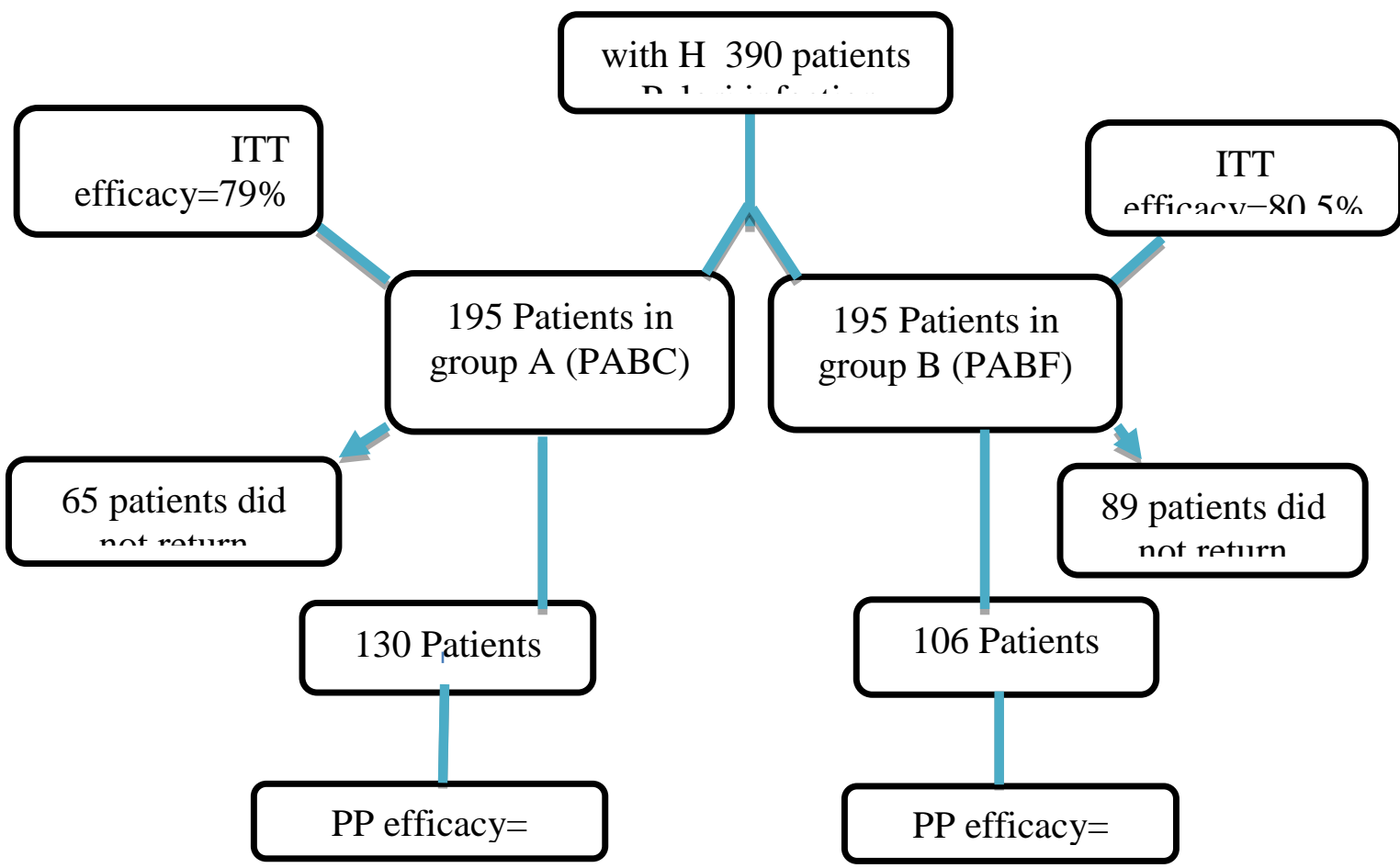

Figure (1): Flow chart of study (ITT: intention to treat; PP: per protocol; PABC: pantoprazole, amoxicillin, bismuth, clarithromycin; PABF: pantoprazole, amoxicillin, bismuth, Furazolidone).

\section{DISCUSSION}

Potential complications of $\mathrm{H}$. pylori infection emphasize on importance of effective eradication of this bacterium and in this regard, antibiotic resistance is a great challenge [22]. Considering ever changing pattern of bacterial resistance, the success rate of eradication declined from more than $80 \%$ in early 90 s to even less than $50 \%$ in recent years $[\mathbf{1 3}, \mathbf{2 3}]$, which is an issue that highlights the importance of seeking for new therapeutic regimens [24].

An optimal anti-HP regimen is defined as one that reliably produces cure rate of $90 \%$ or greater

Alavinejad et al., Afro-Egypt J Infect Endem Dis 2021;11(1):44-50

https://aeji.journals.ekb.eg/

http://mis.zu.edu.eg/ajied/home.aspx 
and an acceptable therapy should reach the cure rate around $85 \%$ to $89 \%$ [25]. Clarithromycin is one of the most commonly used medications in eradicating HP worldwide with variable success rates; however, increasing HP resistant to Clarithromycin has caused concerns about its efficacy during clinical practice $[13,15]$. The resistance rate of $\mathrm{H}$. pylori against clarithromycin in Ahvaz city has been reported to be $24 \%$, which cause this region to consider as a high resistance rate [26].

Based on this resistance pattern, the current study designed to evaluate efficacy of Furazolidone as a potential substitute for clarithromycin in clinical practice. Previously multiple trials with various doses and different regimens have shown that Furazolidone is tolerable and could be efficient for this propose [27, 28]. However, most of them have been single center with fewer participants.

In study of Fakheri et al in 2007, quadruple regimens containing Furazolidone and Clarithromycin compared and there was not any significant difference in eradication rate. They reported success eradication of $84 \%, 85 \%$ in ITT analysis, respectively, and $90 \%$ for both in PP analysis [28] which are comparable to the results of current study. In 2009, Bahari reported eradication rate of $97.9 \%$ by Furazolidone from South east of Iran [29]. Another study from china showed that Furazolidone-containing regimen achieves satisfactory eradication rate of $90.22 \%$ in ITT analysis (95\% CI: 84.0-96.4) and 93.26\% in PP analysis (95\% CI: 87.9-98.6)[30]. These results are differ from others who showed that Furazolidone regimen achieved relatively poor results with PP ranging from $56 \%$ to $85.7 \%$ in Iran [31] and also higher than results of our study. The difference could be related to geographic distribution, culture, population variations and or patients' compliance.

The findings of current study $(80.9 \%$ for clarithromycin and $82.1 \%$ for Furazolidone in PP analysis) were in contrast to a similar study by Rahmani et al. who reported the clarithromycinquadruple efficacy to be higher than Furazolidone-based quadruple therapy $(53.3 \%$ vs. $38.3 \%$ ) [32]. This difference could be explained by high rate of complications and side effects in that study (Headache $61.7 \%$, nausea $46.7 \%$, vomiting $15 \%$, diarrhea $53.3 \%$ ) which could result in sub optimal compliance and subsequently decreased success rate. In clinical practice, the main concern about prescribing Furazolidone in its side effects and fear of poor compliance [33] but in current study, rate of complication was not different between Furazolidone and clarithromycin $(3.1 \%$ in each group). Although it is presumable that some of the cases who did not returned for follow up also suffer from medications side effects.

One of the distinctive features of current study is participation of patients with different clinical diagnosis and sub group analysis. Among cases who suffer from non-ulcer dyspepsia or those who diagnosed with PUD, the eradication rate between 2 therapeutic regimens was comparable and equal but in case of intestinal metaplasia, the story differs and Furazolidone was superior to clarithromycin $(85.7 \%$ vs. $55.6 \%, \mathrm{P}=0.162)$. Intestinal metaplasia is a well-known gastric cancer risk factor $[34,35]$ and if superiority of Furazolidone is proved in future studies, it can be a great harvest for better regimen selection in such cases. Though the number of cases with intestinal metaplasia was not too much and it worth to evaluate in future clinical trials.

One of the limitations of current study is high rate of drop out of participants (65 cases in group A and 89 cases in group B) which could be partly due to potential side effects of therapeutic regimens. These cases consider as therapeutic failure if ITT analysis.

\section{CONCLUSION}

In areas with high rate of resistance to clarithromycin, Furazolidone could be a potential candidate and clarithromycin substitute in HP eradication regimen and in cases with intestinal metaplasia; Furazolidone could be even more efficient and better choice than clarithromycin..

\section{Acknowledgement:}

This article is part of final thesis of Dr Maryam Lajmirnia for her MD degree. Authorship statement: Pezhman Alavinejad, MD as corresponding author; Seyed Saeed Seiedian, $\mathrm{MD}$ as gastroenterologist and main colleague in patients selection; Kave Ebadi Borna, MD as gastroenterologist and main colleague in patients selection; Eskandar Hajiani, MD as clinical consultant; Maryam Lajnirnia as main colleague and DATA collector; and Saeed Hesam as statistician for DATA analysis. 


\section{Ethical considerations}

The study protocol conforms to the ethical guidelines of the 1975 Declaration of Helsinki, so this study approved by ethical committee of Ahvaz Jundishapur University of Medical Sciences in October 2018 (IR. AJUMS. REC. 1397.070) and registered in Iranian randomized clinical trial registration as IRCT 20171203037734N1. Before participation, the method of study explained for all of the participants and they requested to sign a consent form. They were in touch with clinician by phone call and requested to report any potential complication or side effect.

\section{Funding and conflict of interest}

This study approved and endorsed by alimentary tract research center of Ahvaz Jundishapur University of Medical sciences without any financial support.

The authors declare to have any conflict of interest.

\section{REFERENCES}

1. Smith SM, O'morain C, McNamara D. Helicobacter pylori resistance to current therapies. Current Opinion in Gastroenterology 2019 Jan 1; 35(1):6-13. (PMID: 30489412, DOI: 10.1097/MOG.0000000000000497)

2. Go MF. Natural history and epidemiology of Helicobacter pylori infection. Alimentary Pharmacology \& Therapeutics 2002 Mar; 16:315. (PMID: 11849122, DOI: 10.1046/j.13652036.2002.0160s1003.x)

3. Uemura N, Okamoto S, Yamamoto S, Matsumura N, Yamaguchi S, Yamakido M, et al. Helicobacter pylori infection and the development of gastric cancer. New England Journal of Medicine 2001 Sep 13;345(11):784-9. (PMID: 11556297 DOI: 10.1056/NEJMoa001999)

4. Peek RM, Wroblewski LE. Helicobacter pylori Infection and Gastric Cancer. InHelicobacter pylori Research 2016 (pp. 403-421). Springer, Tokyo.

5. Hunt RH, Xiao SD, Megraud F, Leon-Barua R, Bazzoli F, Van der Merwe S, et al. Helicobacter pylori in developing countries. World gastroenterology organisation global guideline. $J$ Gastrointestin Liver Dis 2011 Sep 1;20(3):299304.
6. Bellack NR, Koehoorn MW, MacNab YC, Morshed MG. A conceptual model of water's role as a reservoir in Helicobacter pylori transmission: a review of the evidence. Epidemiology \& Infection 2006 Jun; 134(3):439-49. (PMID: 16512966, PMCID: PMC2870436, DOI: 10.1017/S0950268806006005)

7. Rehnberg-Laiho L, Rautelin H, Koskela P, Sarna S, Pukkala E, Aromaa A, et al. Decreasing prevalence of helicobacter antibodies in Finland, with reference to the decreasing incidence of gastric cancer. Epidemiology \& Infection 2001 Feb; 126(1): 37-42. (DOI:10.1017/ S0950268801005027)

8. Eshraghian A. Epidemiology of Helicobacter pylori infection among the healthy population in Iran and countries of the Eastern Mediterranean Region: a systematic review of prevalence and risk factors. World Journal of Gastroenterology: WJG. 2014 Dec 14;20(46):17618. (PMID: 25516677 PMCID: PMC4265624 DOI: 10.3748/wjg.v20.i46.17618)

9. Nouraie M, Latifi-Navid S, Rezvan H, Radmard AR, Maghsudlu M, Zaer-Rezaii $H$, et al. Childhood hygienic practice and family education status determine the prevalence of Helicobacter pylori infection in Iran. Helicobacter. 2009 Feb;14(1):40-6. (PMID: 19191895 DOI: 10.1111/j.1523-5378.2009.00657.x)

10. Suzuki H, Franceschi F, Nishizawa T, Gasbarrini A. Extragastric manifestations of Helicobacter pylori infection. Helicobacter 2011 Sep;16:65-9. (PMID: 21896088 DOI: 10.1111/j.15235378.2011.00883.x)

11. Franchini M, Veneri D. Helicobacter pyloriassociated immune thrombocytopenia. Platelets. 2006 Jan 1;17(2):71-7. (PMID: 16421007 DOI: 10.1080/09537100500438057)

12. DuBois S, Kearney DJ. Iron-deficiency anemia and Helicobacter pylori infection: a review of the evidence. The American Journal of Gastroenterology. 2005 Feb;100(2):453. (PMID: $15667507 \quad$ DOI: $10.1111 / \mathrm{j} .1572$ 0241.2005.30252.x)

13. De Francesco V, Giorgio F, Hassan C, Manes G, Vannella L, Panella C, et al. Worldwide H. pylori antibiotic resistance: a systematic review. Journal of Gastrointestinal \& Liver Diseases. 2010 Dec 1;19(4). (PMID: 21188333). 
14. Boyanova L, Mitov I. Geographic map and evolution of primary Helicobacter pylori resistance to antibacterial agents. Expert Review of Anti-Infective Therapy 2010 Jan 1;8(1):59-70. (PMID: 20014902 DOI: 10.1586/eri.09.113)

15. Giorgio F, Principi M, De Francesco V, Zullo A, Losurdo G, Di Leo A, et al. Primary clarithromycin resistance to Helicobacter pylori: Is this the main reason for triple therapy failure? World Journal of Gastrointestinal Pathophysiology. 2013 Aug 15;4(3):43. (PMID: 23946886 PMCID: PMC3740258 DOI: 10.4291/wjgp.v4.i3.43)

16. Khashei R, Dara M, Bazargani A, Bagheri Lankarani K, Taghavi A, Moeini M, et al. High rate of $\mathrm{A} 2142 \mathrm{G}$ point mutation associated with clarithromycin resistance among Iranian Helicobacter pylori clinical isolates. Apmis. 2016 Sep;124(9):787-93. (doi.org/10.1111/apm.12567)

17. Shokrzadeh L, Alebouyeh M, Mirzaei T, Farzi N, Zali MR. Prevalence of multiple drug-resistant Helicobacter pylori strains among patients with different gastric disorders in Iran. Microbial Drug Resistance. 2015 Feb 1;21(1):105-10. (PMID: 25303151 DOI: 10.1089/mdr.2014.0081)

18. Siavashi F, Heydarian E, Pourkhajeh AH, Merat $\mathrm{SH}$, ASLSOLEYMANI $\mathrm{H}$, Khatibian $\mathrm{M}$, et al. Susceptibility of various strains of Helicobacter pylori to selected agents.

19. Malekzadeh R, Ansari R, Vahedi H, Siavoshi F, Alizadeh BZ, Eshraghian MR, et al. Furazolidone versus metronidazole in quadruple therapy for eradication of Helicobacter pylori in duodenal ulcer disease. Alimentary Pharmacology and Therapeutics. 2000 Mar 1;14(3):299-304.

20. Graham DY, Osato MS, Hoffman S, Opekun AR, Anderson SY \& Ec-Zimaity HMT. Furazolidone combination therapies for Helicobacter pylori infection in the United States. Aliment Pharmacol Ther 2000; 14: 211-5.DOI: 10.1046/j.13652036.2000.00640.x.

21. Ebrahimi-Dariani N, Mirmomen S, MansourGhanaei F, Noormohammadpoor P, Sotodehmanesh R, Haghpanah B, et al. The efficacy of furazolidone-based quadruple therapy for eradication of Helicobacter pylori infection in Iranian patients resistant to metronidazole-based quadruple therapy. Medical Science Monitor. 2003 Aug 27;9(8):PI105-8.
22. Hajiani E, Alavinejad P, Avandi N, Masjedizadeh AR, Shayesteh AA. Comparison of levofloxacinbased, 10-day sequential therapy with 14-day quadruple therapy for Helicobacter pylori eradication: a randomized clinical trial. Middle East Journal of Digestive Diseases. 2018 Oct;10(4):242. (PMID: 31049172 PMCID: PMC6488509 DOI: 10.15171/mejdd.2018.117)

23. Graham DY, Fischbach L. Helicobacter pylori treatment in the era of increasing antibiotic resistance. Gut. 2010 Aug 1;59(8):1143-53. (PMID: 20525969 DOI: 10.1136/gut.2009. 192757)

24. Njume C, Afolayan AJ, Ndip RN. An overview of antimicrobial resistance and the future of medicinal plants in the treatment of Helicobacter pylori infections. Afr. J. Pharm. Pharmacol. 2009 Dec 1;3(13):685-99. (DOI: 10.5897/AJPP)

25. Graham DY, Lee YC, Wu MS. Rational Helicobacter pylori therapy: evidence-based medicine rather than medicine-based evidence. Clinical Gastroenterology and Hepatology. 2014 Feb 1;12(2):177-86. (doi.org/10.1016/j.cgh.2013. 05.028)

26. Moosavian M, Tajbakhsh S, Samarbaf-Zadeh AR. Rapid detection of clarithromycin-resistant Helicobacter pylori in patients with dyspepsia by fluorescent in situ hybridization (FISH) compared with the E-test. Annals of Saudi Medicine. 2007 Mar;27(2):84-8. (PMID: 17356313 PMCID: PMC6077032 DOI: 10.5144/0256-4947.2007.84)

27. Zhuge L, Wang Y, Wu S, Zhao RL, Li Z, Xie Y. Furazolidone treatment for Helicobacter Pylori infection: A systematic review and meta-analysis. Helicobacter. 2018 Apr;23(2):e12468. (PMID: 29480532)

28. Fakheri H, Malekzadeh R, Merat S, Khatibian M, Fazel A, Alizadeh BZ, et al. Clarithromycin vs. furazolidone in quadruple therapy regimens for the treatment of Helicobacter pylori in a population with a high metronidazole resistance rate. Alimentary Pharmacology \& Therapeutics. 2001 Mar 6;15(3):411-6. (doi.org/10.1046/j.13652036.2001.00931.x)

29. Bahari A, Nezam SK, Karimi M, Firouzeh K, Firouzi F. Comparing furazolidone and tetracycline in quadruple therapy for eradication helicobacter pylori in dyspepsia patients. Gastroenterology and Hepatology from Bed to Bench. $2009 \quad$ May 12;1(1):17-. (doi.org/10.22037/ghfbb.v1i1.17). 
30. Yi DM, Yang TT, Chao SH, Li YX, Zhou YL, Zhang $\mathrm{HH}$, et al. Comparison the cost-efficacy of furazolidone-based versus clarithromycin-based quadruple therapy in initial treatment of Helicobacter pylori infection in a variable clarithromycin drug-resistant region, a singlecenter, prospective, randomized, open-label study. Medicine. 2019 Feb;98(6).

31. Mohammadi M, Attaran B, Malekzadeh R, Graham DY. Furazolidone, an underutilized drug for $H$. pylori eradication: lessons from Iran. Digestive diseases and sciences. 2017 Aug 1;62(8):1890-6. (PMID: 28577244 PMCID: PMC5527993 DOI: 10.1007/s10620-017-4628-5)

32. Rahmani A, Jafari A, Mabrokzadeh H, Asadollahi K, Abangah G, Sayemiri K, et al. Comparison between the effectiveness of Furazolidone and Clarithromycin on eradication of helicobacter pylori among patients with peptic ulcer. Journal of Basic Research in Medical Sciences. 2015 Sep 10;2(4):45-50.
33. Hosseini V, Mokhtare M, Gholami M, Taghvaei T, Maleki I, Valizadeh M, et al. A Comparison between Moderate-and High-dose Furazolidone in Triple Regimens for Helicobacterpylori Eradication in Iran. Middle East Journal of Digestive Diseases. 2014 Oct;6(4):195. (PMID: 25349682 PMCID: PMC4208927)

34. Busuttil RA, Boussioutas A. Intestinal metaplasia: a premalignant lesion involved in gastric carcinogenesis. Journal of Gastroenterology and Hepatology. 2009 Feb;24(2):193-201. (PMID: $19215332 \quad$ DOI: $\quad 10.1111 / \mathrm{j} .1440-$ 1746.2008.05774.x)

35. González CA, Sanz-Anquela JM, Gisbert JP, Correa P. Utility of subtyping intestinal metaplasia as marker of gastric cancer risk. A review of the evidence. International Journal of Cancer. 2013 Sep 1;133(5):1023-32. (PMID: 23280711 PMCID: PMC3732516 DOI: 10.1002/ijc.28003). 